\title{
Breaking Out of Surveillance Silos: Integrative Geospatial Data Collection for Child Injury Risk and Active School Transport
}

Laura Schuch, Jacqueline W. Curtis, Andrew Curtis, Courtney Hudson, Heather Wuensch, Malinda Sampsell, Erika Wiles, Mary Infantino, and Andrew J. Davis

\begin{abstract}
The preponderance of active school transport (AST) and child injury research has occurred independently, yet they are inherently related. This is particularly true in urban areas where the environmental context of AST may pose risks to safety. However, it can be difficult to make these connections due to the often segregated nature in which these veins of research operate. Spatial video presents a geospatial approach for simultaneous data collection related to both issues. This article reports on a multi-sector pilot project among researchers, a children's hospital, and a police department, using spatial video to map child AST behaviors; a geographic information system (GIS) is used to analyze these data in the environmental context of child pedestrian injury and community violence.
\end{abstract}

KEYWORDS Geographic information system (GIS), Spatial video, Active school transport (AST), Child injury prevention, Urban health

\section{BACKGROUND}

Public health researchers and practitioners have been challenged to adopt integrative, transdisciplinary approaches to what are ultimately systemic, interrelated problems. ${ }^{1-3}$ For example, Leischow and colleagues ${ }^{2}$ use examples of weather forecasting and public behavioral responses, as well as controlling spread of pandemic influenza as two areas where multi-sector, transdisciplinary collaboration is essential for positive public health outcomes. In the same vein, achieving safe active living for children requires a coordinated, collaborative effort across multiple sectors, such as health care providers, city government, and police officers. However, effectively responding to this call is difficult for a number of reasons, one of which is the silos in which these sectors usually operate. In order to investigate methods for breaking down these silos and taking an integrative approach, Akron Children's Hospital, Akron Police Department, and the GIS Health and Hazards Lab collaborated on a child injury surveillance project using child injury data, police data, and spatial video technology to survey recreational

Schuch, Curtis, and Curtis are with the GIS Health \& Hazards Lab, Department of Geography, Kent State University, Kent, OH, USA; Hudson and Wuensch are with the Akron Children's Hospital, Akron, OH, USA; Sampsell, Wiles, and Infantino are with the Akron $(\mathrm{OH})$ Police Department, Akron, OH, USA; Davis is with the School of Sport Science \& Wellness Education, College of Health Professions, University of Akron, Akron, OH, USA.

Correspondence: Jacqueline W. Curtis, GIS Health \& Hazards Lab, Department of Geography, Kent State University, Kent, OH, USA. (E-mail: jmills30@kent.edu) 
and school sites in order to map spatial patterns of active school transport (AST) and injury risk behaviors in their environmental context. Spatial video, which is video embedded with global positioning system (GPS) coordinates, ${ }^{4}$ enables empirical observation of the following: (a) engagement in AST, (b) risk behaviors in AST, and (c) the environmental context of AST." As there is a GPS coordinate for every one second of video, visual behaviors can be digitized into a geographic information system (GIS).

To illustrate the potential of this method, this paper will focus on the results of AST and injury surveillance surrounding International Walk to School Day on October 8, 2014. The study site is one inner-city urban elementary school in Akron, Ohio. Most of the students who attend this school live in the surrounding area which is characterized by the highest obesity rates in the city; they also do not have access to bussing. ${ }^{\dagger}$ Based on these two situations alone, it would seem ideal to encourage AST. However, this area also exposes children to elevated risk of injury. Using the Haddon Matrix as a guide, the physical and socio-cultural environments to which these children would be exposed during AST deserves serious consideration. ${ }^{5,6}$ For example, in the city of Akron, 57 child pedestrians have been injured due to collision with a car over the past two and a half years, but of these, 19 (approximately one third) occurred in the 2-mi buffer around this school. This same area also holds several city-wide hot spots for shooting and for overall elevated child injury incidence (Fig. 1).

Furthermore, the physical environment also poses risks to these children. For example, high traffic volumes, difficult street crossings, deteriorated sidewalks, vegetation overgrowth, and lack of snow removal in winter were identified as physical barriers to walking and biking to school as well as adding to parental fear of crime. ${ }^{7}$

\section{LITERATURE REVIEW}

It is widely accepted that AST, defined as active modes of traveling to school such as walking and bicycling, yields a number of positive health outcomes for children. ${ }^{8-11}$ Though AST is generally viewed as a positive behavior, it can also expose children to risks such as violence, substance promotion/abuse, air pollution, and injury. ${ }^{12-20}$ One way to more holistically study the benefits-risks relationship in AST is to think outside typical data surveillance silos and by integrating data collection and analysis that links behaviors in the environments in which they occur. With its ability to overlay different spatial layers from different sources (e.g., hospital, police) and to analyze the relationships within, between, and among these layers, GIS can be an effective tool for such multi-sector data integration. In addition, the emergence of GPS and GPS-enabled instruments creates the ability to systematically collect characteristics of the built and social environments at fine-spatial scales not previously accessible to researchers. Though a number of studies have employed GPS and GPS-enabled technologies in health investigations, ${ }^{21-23}$ our study is focused solely on their use in understanding AST and child injury surveillance.

\footnotetext{
**This paper reports only on the behavioral observations gathered with spatial video.
}

$\dagger$ For students who live within 2 mi of their school, Ohio State Law does not require bussing, though districts can choose to provide this service within the 2-mi zone. Akron public schools does not provide transportation to students living within $2 \mathrm{mi}$ of their school http://www.Akronschools.com/group/ departments/Transportation+Services 


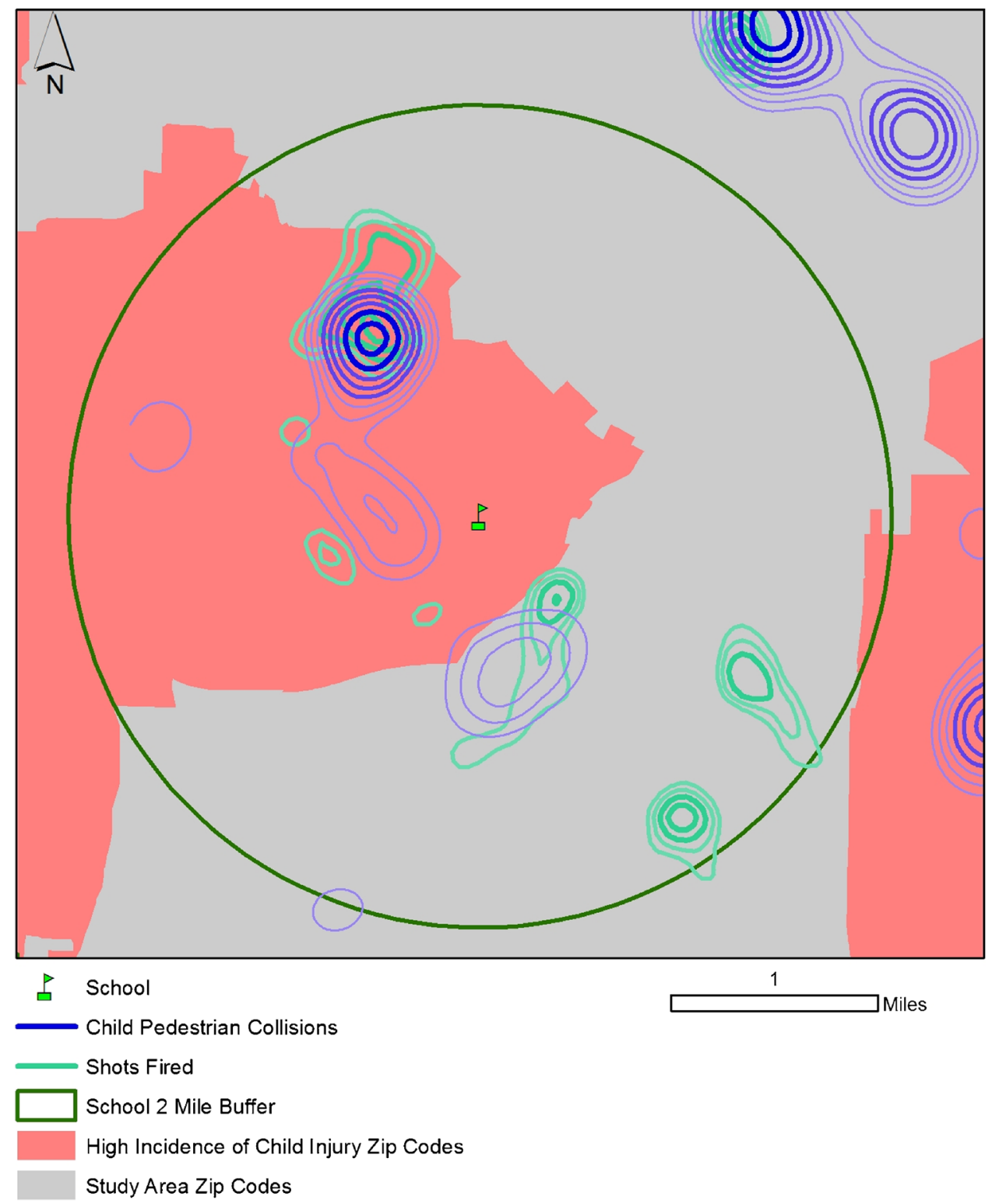

FIG. 1 An example of characteristics of the injury risk environment for AST. Zip codes with highest incidence of child injury (2013) are based on data from Akron Children's Hospital and from the Ohio Hospital Association (OHA). These data consist of inpatient, outpatient, and emergency department visits. For this project, only patients who are between the ages of 0 and 18 years and reside in Summit County are collected. Locations of child pedestrians injured by automobile collisions (2013first half of 2015) and shots fired (2010-2014) are identified through Akron Police Department data.

\section{Methodological Approaches to AST and Injury Surveillance}

Current understanding of AST behavior has been developed through the use of several forms of data collection: surveys, including travel diaries, ${ }^{24-28}$ interviews, and GPS data loggers ${ }^{23,29-32}$ or some combination of these approaches. ${ }^{10,11,33-36}$ Existing methods vary in their ability to answer questions such as where children 
engage in AST (what routes), why these routes are selected, and when AST is used (e.g., time of day, day of week, seasonal variations). They offer different advantages, as well as limitations in advancing knowledge of AST. For example, phone, mail, or online surveys enable data collection on a large number of participants, but obtaining geographic specificity and explanation of mobility decisions is difficult to capture. Travel diaries can include destinations and times, but not routes and explanations, and can be limited by the retrospective self-reporting approach which relies on the participants' unreliable recall. ${ }^{37,38}$

Explicitly spatial approaches (GIS, GPS data loggers, and GPS-enabled sensors) have emerged as an approach aimed at understanding the environment-behavior nexus in AST over the past decade. Falb and colleagues ${ }^{39}$ used GIS with census data to estimate the number of children who could reasonably be expected to walk to school in Georgia. Duncan and Mummery ${ }^{33}$ used GPS data loggers to map the route to school taken by participating children and then compared this route and its associated barriers to a route map created from recall in a GIS. They found that GPS provided more accurate routes, which is to be expected, and therefore support use of GPS for accurate collection of routes used in AST. Cooper et al., ${ }^{29}$ Southward et al., ${ }^{30}$ Lee and $\mathrm{Li}^{36}$ Voss et al., ${ }^{31}$ and Klinker et al. ${ }^{32}$ use GPS data loggers with accelerometers to determine the contribution of the walk to school to child physical activity (PA). This approach enables delineation of the routes taken and the PA that occurs in places along this route. GIS and GPS have also been employed to measure distance between home and school in school travel mode behavior, ${ }^{40,41}$ while Buliung et al. ${ }^{42}$ investigated the use of GIS-based shortest path networks between home-school and those reported through sketch maps submitted by participants. Route discordance was identified between the two approaches, indicating the need to use actual routes rather than shortest-path algorithms. Harrison and colleagues ${ }^{43}$ investigated a similar question: is there a difference between GIS modelled shortest routes and routes collected through GPS data loggers? Again, the GPS-based routes of actual travel were different from those computed by the shortest-path algorithm. More recently, several studies have moved to integrate this work on travel path identification and measurement with investigation of built environment characteristics around schools and along AST routes used by children. ${ }^{44-46}$

One related vein of research that has focused data collection more on behavior in the behavior-environment calculus is child pedestrian safety studies. Direct observation has been used as a tool to collect data on behavior in child injury surveillance and prevention studies, though this approach has received relatively little attention in the published research in AST. In 1974, Routledge and colleagues ${ }^{47}$ tape recorded their observations of children's pedestrian behaviors on their walk home from school. DiGuiseppi and colleagues ${ }^{48}$ used direct observation of bicycle helmet wearing among children at different sites and across different income levels in two cities before and after a helmet wearing campaign. Cote and colleagues ${ }^{49}$ used a similar technique to assess use of helmets before and after implementation of a helmet law in Maryland. Rivara and colleagues ${ }^{50}$ observed child street crossing behaviors before and after a school training intervention in which safety behaviors were taught. Observers stood outside of the study school and noted the presence/ absence of certain behaviors (e.g., stopping at curb, looking left, right, left prior to crossing). However, there was no spatial component to the study, such as mapping behaviors by location. This approach was undertaken by Sisiopiku and Akin ${ }^{51}$ to 
show "snapshots" of pedestrian volume at specific locations along their observation sites. Furthermore, Hine ${ }^{52}$ uses video recording of pedestrian behaviors at study sites to show participants traffic flow and assess their perceptions. Despite the contributions of this work, the approach has inherent limitations in time consumption and in single or limited use due to what is coded at the time of observation. This situation argues for a more systematic, replicable, and archival form of data collection.

Overall, the integration of geospatial technology in child injury surveillance has also advanced apace, but primarily along a separate trajectory from that of AST. In the past 15 years, child injury surveillance research has increasingly included explicit use of GIS for cross-sectional studies mapping locations of injuries and providing spatial analysis of their environmental and social correlates. ${ }^{53-59}$ However, within these types of studies, the spatial unit of analysis has commonly been the census tract, zip code tabulation area, or other relatively large and diverse area both in terms of physical infrastructure and in demographic characteristics. Furthermore, despite the substantive and methodological contributions of these studies, a need remains for expansion into longitudinal investigations of these behaviors and relationships, as well as those focused on evaluation of specific interventions. ${ }^{8,60-62}$ Spatial video is an emergent geospatial approach that can be employed to address these needs.

\section{Spatial Video}

Spatial video enables the walking or driving path to be captured visually with observable features being geolocated. Typically, this video is displayed in a window that concurrently shows the location of each frame. What is seen can be mapped. This emergent geospatial technology has been employed in a wide variety of settings and for different studies, from understanding wildlife habitats, patterns of postdisaster damage, and recovery to physical disorder and environmental health risks. ${ }^{4,63-65}$ In these applications, the aim has been to link features of the natural or human environment to their real-world location in order to enable mapping and spatial analysis of dynamic or ephemeral data, particularly in challenging environments.

The behaviors of children are certainly dynamic and ephemeral, which can make systematic observation difficult. However, spatial video provides one approach to address this problem. Not only can it be used to collect behaviors in a particular place to understand patterns across space, but by repeat data collection in the same locations, analysis can move from purely cross-sectional to longitudinal which is particularly important in understanding changing behaviors over time and in response to intervention. ${ }^{66}$ Whereas the empirical research to date has primarily focused on behavioral or environmental variables, spatial video enables the integration of the two in place. Are children engaged in active school travel, in what forms, where, and when? A single data collection trip can be used to code these behavioral and environmental variables in a format suitable for spatial analysis.

In addition to enabling collection of dynamic and ephemeral behavioral data on children, spatial video is a cost-effective method for longitudinal studies where the map is used as the archive. The GPS track linked to the video means that the route of surveillance is clearly marked and can be followed repeatedly over multiple time periods. Each of these videos can easily be accessed to code data aligned with future projects not considered at the time of collection. For example, if the spatial video data is initially used to map the presence of children walking or biking, but then 
changes are made to the sidewalks in the area, the video can be retrieved to map sidewalk presence and quality before these changes occurred to investigate the relationship between this built environment feature and active transport behavior. Once the data are collected, these types of longitudinal and archival applications are both beneficial to building knowledge of the linkages between environment and behavior and in a cost-effective manner.

\section{METHODS}

\section{Study Site}

The study site is a Community Learning Center (CLC) and its surrounding environment located in Akron, Ohio (Fig. 2). The CLC was selected due to its location in a Zip Code Tabulation Area (ZCTA) of elevated child injury incidence and child obesity. A ZCTA is a census unit that approximates a zip code (US Postal Service designation), but have been derived for different purposes and can actually encompass different populations. ${ }^{67}$ Therefore, the CLC is in an area where encouraging AST is needed, but interventions should be considered in the context of a high injury risk environment (Figs. 1 and 2).

The ZCTA in which this CLC is located has an under-19 population of 1887. However, in 2013, 714 injuries" were reported for this population residing in the ZCTA. In addition to injury data, the Akron Police Department (APD) collects data on all incidents where a juvenile is a victim. Examination of these data indicates that for the same time period, this area appears as a hot spot for juvenile victimization in general, but with looking at call for service data, this is also a hot spot of community violence (e.g., shooting) (Fig. 1).

The CLC provides educational services to children in kindergarten to fifth grade. Adjacent to the center is a preschool program. The 2014-2015 enrollment at the CLC was 328 students, with $100 \%$ of the student population considered at an economic disadvantage. ${ }^{68}$ Census demographic characteristics for the zip code in which the CLC is located identifies the population as $87.6 \%$ non-Hispanic Black, $7.4 \%$ White, $1.5 \%$ Hispanic, $3.3 \%$ two or more races, and less than $1 \%$ for all other categories. ${ }^{69}$ Approximately $72 \%$ percent of families with children under 18 years have a female single head of household. The percentage of families with children under 18 years with income below the poverty rate in the last 12 months is $59.3 \%$. $^{69}$

*nitial equipment purchase is relatively inexpensive (each camera is priced around $\$ 250$ and the only additional purchase is micro-SD cards); the costs for data collection beyond this equipment are fuel/mileage to conduct a driving survey. Once collected, the data can be mapped using a combination of Contour Storyteller to "drive" the survey site in a computer lab and Google Earth to map what is observed in the video. Both pieces of software are free. Coding can be accomplished in Google Earth and then converted into GIS. Based on these relatively low costs and minimal training needed to survey and map observations, this approach can be a component of local surveillance measures led by local public health practitioners. It can build local capacity for surveillance; with widespread adoption, it can also be a part of a larger distributed sensor system.

§US Census (2012), 5-year estimates

"Ohio Department of Health 
a)

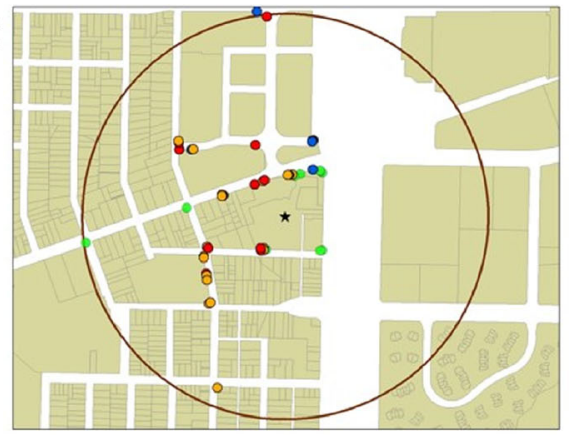

c)

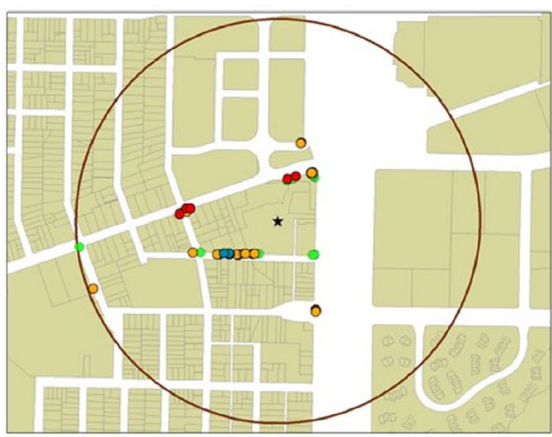

e)

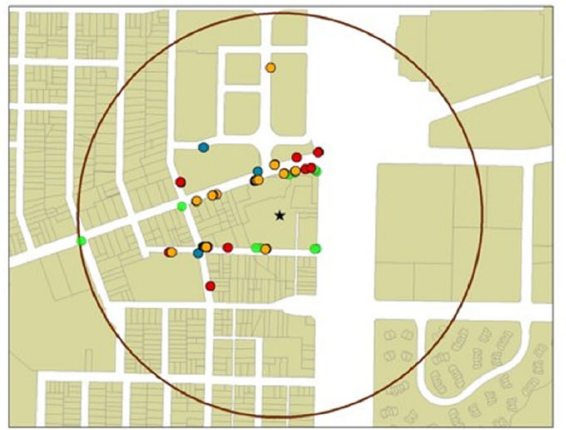

b)

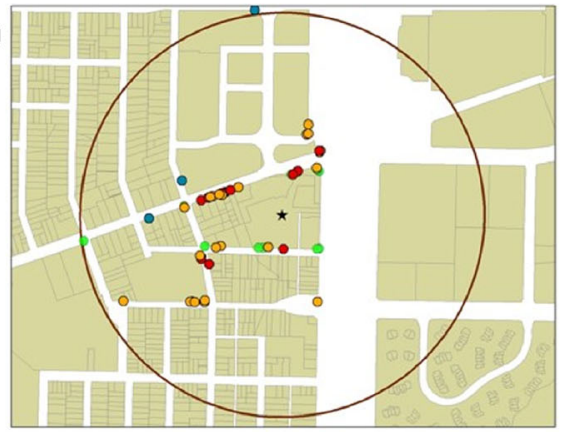

d)

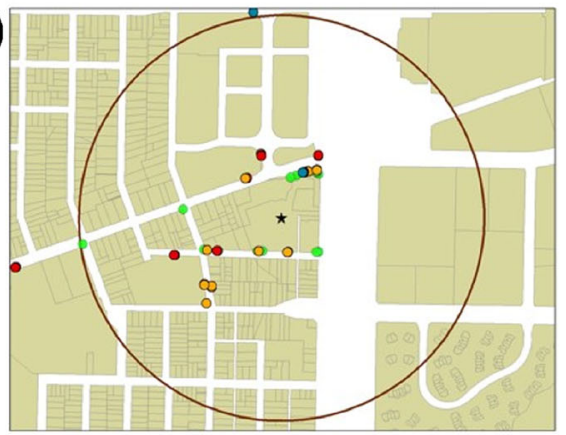

Age of Child

5 and under

O 6 to 10

- 11 to 14

Safety Patrol

$\star$ Survey site

.25 mile area

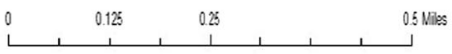

FIG. 2 Example of maps resulting from spatial video surveys at 8.00 a.m.: a Day 1 (preintervention/baseline), b Day 2 (intervention), c Day 3 (1 day post-intervention), d Day 4 (3-week post-intervention), e Day 5 (4-week post-intervention).

\section{Spatial Video Surveys}

Spatial video capture involved the use of four Contour action sports cameras ${ }^{70}$ mounted on both sides of a vehicle on the rear passenger windows, directed outward. The cameras have a built-in GPS which provides a coordinate track of the route driven to accompany the video. Spatial video recorded a quarter-mile area around the school for a 3-day sequence with two longer two comparison runs during the fall of 2014. Data were captured pre-intervention, on the day of the intervention and the day after. In addition, 3-week and 4-week post-intervention follow-ups were collected. Two time periods were collected for each day; during the half-hour before school starts in the morning and the half-hour after school ends in the afternoon. The route consisted of first driving the streets along the perimeter of the school and expanding out within a quarter-mile radius. The time to complete 
one drive around the perimeter of the study site was 4 min which resulted in multiple passes of the CLC during the half-hour collection time period. In addition, the children arrive to school and leave from school at several access points which requires constant movement to record the children as they travel.

\section{Coding}

The video from each collection period was downloaded and viewed in Contour Storyteller software. ${ }^{70}$ Characteristics associated with each child, or data point, were selected to be digitized into ArcGIS $10.2^{71}$ as a point for the location of each child. In order to eliminate the possibility of duplicate coding during a data collection period, distinguishing characteristics of each child were observed and noted (e.g., certain clothing characteristics). At the same time, each point received the following attributes: the approximate age group ( 5 years and under, 6 to 10 years, and 11 to 14 years), whether or not the child was alone, the presence of an accompanying adult, the observed activity (walking, biking), and any unsafe behaviors (no helmet if biking, climbing fence, roughhousing). The date and time of video collection was also documented within the attribute table. For each day and time period, preliminary analyses were conducted to summarize the data based on the coded variables, and mapping of locations of observed children was completed for each day and time period. The locations of school safety patrol, both students and adults, were visualized spatially into a map. The children were categorized by age group and mapped accordingly. The types and locations of unsafe behaviors were also mapped.

\section{RESULTS}

\section{Active School Transport}

Maps were created visualizing the locations of subjects by age, as seen in Fig. 2, and also by observed activity such as walking, playing (includes running), biking or riding, or standing. Of the 562 observations, 480 were walking, 45 playing, 30 standing, and seven were riding (two on bicycles). Commonalities among the maps in Fig. 2 show a pattern of observed subjects concentrated along the streets which border the CLC, with scant subjects recorded at the edges of the study area, or beyond. The spatial pattern for the time period immediately after school is similar to that from the afternoon of 1 day post-intervention, with an increase in the number of subjects beyond the extent of the CLC perimeter streets. As shown in Fig. 2, the divided highway which transects the study area (shown as a white space east of the study site) serves as a barrier for pedestrian travel. The properties east of the highway are mostly commercial, but there are cluster homes in the southeast section of the study area.

Table 1 provides summary statistics for the 5 days of data collection. From this, we can see the total number of subjects observed, whether the observation occurred in morning or afternoon, the estimated age and whether the subject was viewed alone, with another subject or with an adult. With the exception of day 5, there are substantially more subjects observed in the afternoon. Days 1, 3, and 4 have more than double the number of subjects in the afternoon as compared to the morning. The estimated age categories of 5 years and younger, 6 to 10 years, and 11 to 14 years show that a greater number of subjects were age 6 to 10 years on days 1 to 3 and 11 to 14 years on days 4 and 5. As seen in Fig. 2, 51 subjects are completely 


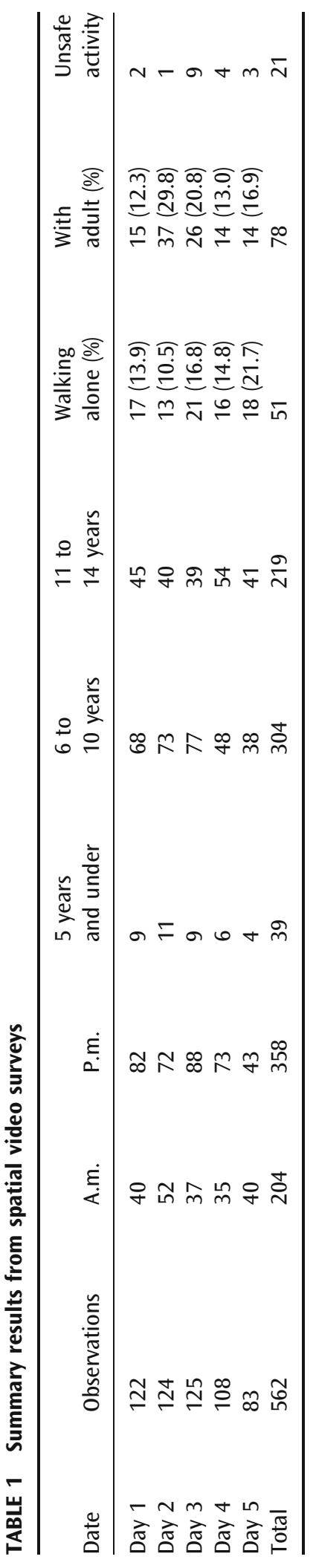


alone, 78 are with an adult and 433 are with another subject. Day 2, the day of the intervention, has both the highest number of supervised children and the lowest number of children commuting alone.

\section{Injury Surveillance}

Visualization of potential unsafe behaviors observed in the spatial video includes the following: riding a bicycle without a helmet, climbing fences, rough play (wrestling, sword fighting with large sticks), unsafe street crossing (directly in front of cars, not in a crosswalk), and walking in the street when a sidewalk is present (Fig. 3).

The overall number of unsafe observations is 21 , which represents $3.7 \%$ of the total. The majority, $85.7 \%$, of the unsafe behaviors occurred in the afternoon. The temporal distribution, by day, is as follows: day $1-2$ cases, day $2-1$ case, day $3-9$ cases, day $4-4$ cases, and day $5-3$ cases. The day after the intervention, day 3 , had $42.9 \%$ of the unsafe behaviors. Out of the 21 instances of unsafe activity, only one was in the youngest age group. Eight subjects were ages 6 to 10 years leaving 12 subjects $(57.1 \%)$ in the 11 to 14 years group. Another result from these surveys is that children who were riding bicycles were doing so without wearing helmets. Of note, however, is that the spatial video did pick up that helmets were left lying on the ground.

\section{DISCUSSION}

Using geography as a framework to address this challenge means looking at multiple health outcomes in place, coalescing efforts in data collection, analysis, and

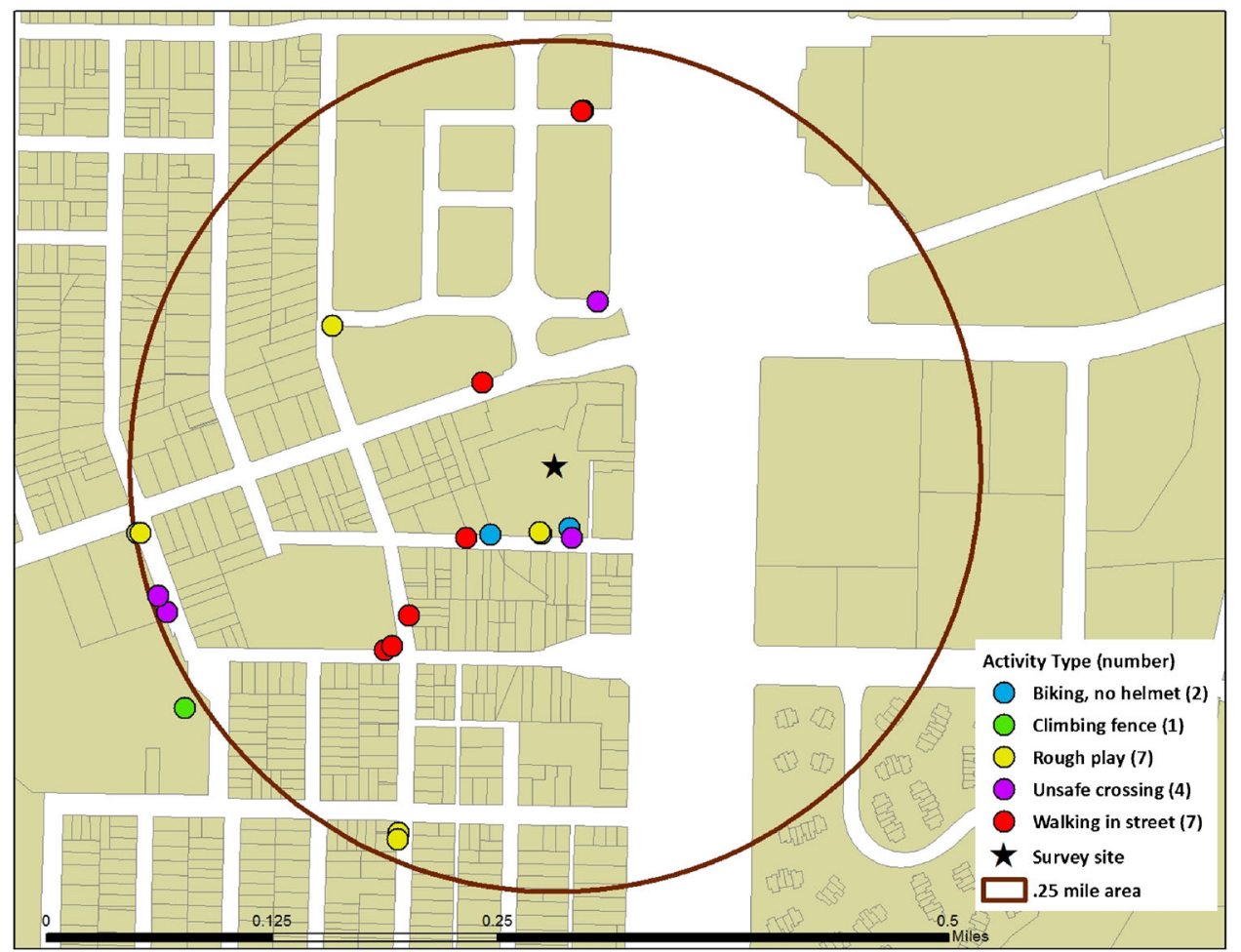

FIG. 3 Observed unsafe behaviors from all spatial video surveys. 
intervention that operate with an understanding of local ecology. With spatial video technology, what is observed can be mapped. Furthermore, these observations can be analyzed over space and time to identify patterns of behavior in place. These data would otherwise be difficult to obtain without spatial video technology due to the dynamic and ephemeral behaviors of children while actively traveling to and from school.

\section{Active School Transport}

Davison and colleagues ${ }^{8}$ note that programs, such as Safe Routes to School and the Walking School Bus, lack evaluation. Spatial video is a cost-effective way to monitor observable commuting behaviors in areas where these programs have been initiated. Using this approach in the current study, more children were observed walking home from school in the afternoon than to school in the morning. This temporal pattern mirrors the findings of Wong and colleagues. ${ }^{28}$ The observed trend may partially be due to the nature of data collection in the afternoon in which subjects originate from one point, the CLC, and spread outward. This is opposed to the morning where subjects are traveling to the CLC from many different locations in the study area. Capturing the movement of the subjects is more difficult in the morning given the greater possible points of origination.

In looking at the overall trend in the number of subjects commuting to school as observed, the decrease in subjects on days 4 and 5 may be due to the change in weather, which resulted in more children being driven to school. Data collection occurred in autumn, and the temperatures and amount of morning sunlight decreased over the 4-week period. In considering the trends and possible effects of the safe routes to school intervention, the trend shown in Table 1 demonstrates an increase in the number of children walking to school, walking with an adult and other children on days 1 and 2, but the trend moves in the opposite direction 1 day post-intervention. Days 4 and 5 (representing weeks 3 and 4 post-intervention) show that the number of children walking with an adult has diminished and the number of children walking alone has increased, as compared to day 2. In fact, the percentage of children walking alone is highest on day 5. The effect of the intervention may have lessened over time.

\section{Injury Surveillance}

The number of children engaging in potentially unsafe behaviors is governed by ability of the researcher to be in the location when the behavior is occurring. The numbers presented here are most likely an underestimation of the actual amount. Only two children were observed riding a bicycle, which may be indicative of the preferred mode of transport as walking, a lack of availability to bicycles, or an administrative constraint by the CLC regarding riding bikes to school. Even so, neither of the observed subjects were wearing a helmet.

The overall increase in unsafe behaviors observed in the afternoon could be a result of the greater number of children observed in the afternoon. The day of the intervention had the least number of observed unsafe activities, only one, as compared to the day after the intervention with nine. This increase may be reflective of the decrease in number of children traveling with an adult observed on days 3 to 5. The influence of adult presence on unsafe behavior is an area that warrants further investigation in future studies as well as the role of traveling in groups on behavior. 


\section{Limitations}

Despite the potential of spatial video to enable new integrative knowledge of active school transport behaviors and child injury surveillance, the approach also has a number of limitations that should be considered, such as constraints in data collection and coding (assigning attributes to each subject). First, spatial video is limited by the resolution and angle of the lenses. Though the cameras are high definition and have fish-eye lenses, which provide clear visibility on each side of the vehicle, they are not omnidirectional which creates $360^{\circ}$ imagery (e.g. Google Streetview). However, in the case of observing numbers and behaviors of children commuting to and from school, this issue is a minimal limitation to quality data collection. The subjects are clearly observable.

While the process of collecting spatial video presents few difficulties, there are challenges related to capturing behaviors of individuals that are in motion throughout a study area. The route driven by the vehicle is dictated by traffic flows around the study site, which may not correspond with the route taken by walking subjects. Additionally, the ability to capture all of the potential subjects that are in route to the study site during the time period of the data collection is limited by the inability to be in more than one location at a time. Likewise, subjects may or may not follow the shortest or most efficient path to the study site. One alternative to mobile collection is to use stationary cameras positioned proximate to the CLC in areas of entry and exit. Fixed cameras would decrease the likelihood of capturing the same subject twice and increase the number of subjects captured; however, the nuances of the influence of environmental context on behavior may be lost. In the fixed camera scenario, every subject walking in view of the camera is exposed to the same environmental conditions. Advances in this application have been made by Hipp and colleagues by leveraging the Archive of Many Outdoor Spaces (AMOS) imagery with crowd-sourced coding through the Amazon Mechanical Turk. ${ }^{72}$ While such an approach is clearly beneficial to compare behavior among subjects, and in one place over time (e.g., what happens to behavior with the addition of a bike lane?), the interaction with the environment along a route is not captured. As students converge on the CLC in the morning or depart in the afternoon, they each follow a different pathway, and the context of this path may affect behavior. For example, the majority of unsafe behaviors shown in Fig. 3 would not have been recorded on a fixed camera proximate to the school. Furthermore, the adult supervision provided by CLC crossing guards may normalize behavior near the CLC. In addition, unless the stationary cameras are adequately disguised, the subjects may realize they are being recorded and adjust behavior accordingly. However, even when using mobile video data collection, advances in image classification through machine learning could help expedite what is currently a time-consuming coding process through identification of individuals or behaviors. ${ }^{73}$

As mentioned previously, the driven route immediately around the site required approximately 4 min to complete, which did provide the ability to capture many of the subjects more than once. However, multiple recordings of one subject also presented a challenge in coding as questions arose as to where to assign the location for subjects with multiple instances. Furthermore, spatial video data collection employs the use of cameras on the left and right sides of the vehicle which requires viewing and coding of video from each side. Subjects often appear in more than one video, especially if they cross a street, which necessitates cross-checking between videos to eliminate double counting. As a resolution, the first appearance of a subject as determined by recording time was used for coding and analysis. The 
possibility exists that a subject may exhibit varying behaviors from the initial appearance in the video which was not coded and mapped. With all of these limitations, however, any error that is introduced with the current data collection and coding procedures would be similar in pre- and post-assessment and, therefore, possibly a less important issue for intervention impact detection.

In addition to these limitations are the ethical considerations of this approach. Publicly observable, raw video or images from these videos are never released, but are stored on a secured server accessed only by limited project personnel. Only map products and tables are released (de-identified, points, or clusters on a map) that do not reveal home locations of children; children must be on a sidewalk or other public space to be coded (not in home property). Furthermore, this surveillance method is applied only in areas where one would expect to see children. Finally, there is always the option of not releasing maps publicly, but only using them for internal evidence in intervention design and implementation.

\section{CONCLUSIONS}

The use of spatial video enhances studies of AST and injury surveillance through the ability to not only record environmental characteristics and conditions but also document behaviors exhibited by the subjects. The multi-day and several postintervention data collection efforts in this study provide a model of longitudinal data collection that can monitor spatial and behavioral patterns and change over time. Specifically, this study demonstrates the diurnal nature of AST and pre-during-post intervention effects of an injury prevention intervention effort.

Spatial video surveys offer unique insight into the dynamic and ephemeral behaviors of children along the route to school. This approach enables spatial and spatio-temporal analyses to examine risks in place and also changes in these risks in response to intervention. Despite the limitations and need for cognizance of ethical implications, spatial video presents an opportunity for advancing understanding of AST along with providing an evidence base for targeted primary prevention of child injuries.

\section{ACKNOWLEDGMENTS}

This work is funded either in whole or in part by a grant awarded by the Ohio Department of Health, Bureau of Healthy Ohio, Violence and Injury Prevention Program and as a sub-award of a grant issued by the Ohio Department of Health under the Preventive Health and Health Services Block Grant, grant award number 3B01DP009042-13S1 and CFDA number 93.991. National Institute of Justice, Office of Justice Programs Part of this project was supported by Award No. 2013R2-CX-0004, awarded by the National Institute of Justice, Office of Justice Programs, U.S. Department of Justice. The opinions, findings, and conclusions or recommendations expressed in this publication are those of the authors and do not necessarily reflect those of the Department of Justice.

\section{REFERENCES}

1. Satterfield D, DeBruyn LM. The malignment of metaphor: silos revisited-repositories and sanctuaries for these times. Am J Prev Med. 2005; 29(3): 240-241. 
2. Leischow SJ, Best A, Trochim WM, et al. Systems thinking to improve the public's health. Am J Prev Med. 2008; 35(2): S196-S203.

3. Kohl HW, Craig CL, Lambert EV, et al. The pandemic of physical inactivity: global action for public health. Lancet. 2012; 380(9838): 294-305.

4. Mills JW, Curtis A, Kennedy B, Kennedy SW, Edwards JD. Geospatial video for field data collection. Appl Geogr. 2010; 30(4): 533-547.

5. Haddon W Jr. A logical framework for categorizing highway safety phenomena and activity. J Trauma Acute Care Surg. 1972; 12(3): 193-207.

6. Haddon W, Suchman EA, Klein D. Accident research-methods and approaches. New York: Harper and Row; 1964.

7. TransSystems Corporation. Akron public schools district-wide travel plan. Ohio: Department of Transportation; 2014.

8. Davison KK, Werder JL, Lawson CT. Peer reviewed: children's active commuting to school: current knowledge and future directions. Preventing chronic disease. 2008; 5(3): A100.

9. Faulkner GE, Buliung RN, Flora PK, Fusco C. Active school transport, physical activity levels and body weight of children and youth: a systematic review. Prev Med. 2009; 48(1): 3-8.

10. Larouche R, Chaput J-P, Leduc G, et al. A cross-sectional examination of sociodemographic and school-level correlates of children's school travel mode in Ottawa, Canada. BMC Public Health. 2014; 14(1): 497.

11. Larouche R, Saunders TJ, Faulkner GEJ, Colley R, Tremblay M. Associations between active school transport and physical activity, body composition and cardiovascular fitness: a systematic review of 68 studies. J Phys Act Health. 2014; 11(1): 206-227.

12. Purugganan OH, Stein RE, Silver EJ, Benenson BS. Exposure to violence among urban school-aged children: is it only on television? Pediatrics. 2000; 106(Supplement 3): 949953.

13. Loukaitou-Sideris A, Eck JE. Crime prevention and active living. Am J Health Promot. 2007; 21(4s): 380-389.

14. Schofield GM, Gianotti S, Badland HM, Hinckson EA. The incidence of injuries traveling to and from school by travel mode. Prev Med. 2008; 46(1): 74-76.

15. Xue J, McCurdy T, Burke J, et al. Analyses of school commuting data for exposure modeling purposes. J Expo Sci Environ Epidemiol. 2010; 20(1): 69-78.

16. Pollack KM, Kercher C, Frattaroli S, Peek-Asa C, Sleet D, Rivara FP. Toward environments and policies that promote injury-free active living-it wouldn't hurt. Health Place. 2012; 18(1): 106-114.

17. Curriero FC, James NT, Shields TM, et al. Exploring walking path quality as a factor for urban elementary school children's active transport to school. J Phys Act Health. 2013; 10: 323-334.

18. Gropp K, Janssen I, Pickett W. Active transportation to school in Canadian youth: should injury be a concern? Inj Prev. 2013; 19(1): 64-67.

19. Rothman L, Buliung R, Macarthur C, To T, Howard A. Walking and child pedestrian injury: a systematic review of built environment correlates of safe walking. Inj Prev. 2014; 20(1): 41-49.

20. Singleton A. A GIS approach to modelling CO2 emissions associated with the pupilschool commute. Int J Geogr Inf Sci. 2014; 28(2): 256-273.

21. Kerr J, Duncan S, Schipperjin J. Using global positioning systems in health research: a practical approach to data collection and processing. Am J Prev Med. 2011; 41(5): 532540.

22. Maddison R, Mhurchu CN. Global positioning system: a new opportunity in physical activity measurement. Int J Behav Nutr Phys Act. 2009; 6(1): 73.

23. Krenn PJ, Titze S, Oja P, Jones A, Ogilvie D. Use of global positioning systems to study physical activity and the environment: a systematic review. Am J Prev Med. 2011; 41(5): 508-515. 
24. Merom D, Tudor-Locke C, Bauman A, Rissel C. Active commuting to school among NSW primary school children: implications for public health. Health Place. 2006; 12(4): 678-687.

25. McDonald NC. Active transportation to school: trends among US schoolchildren, 19692001. Am J Prev Med. 2007; 32(6): 509-516.

26. McDonald NC. Critical factors for active transportation to school among low-income and minority students: evidence from the 2001 National Household Travel Survey. Am J Prev Med. 2008; 34(4): 341-344.

27. Arango CM, Parra DC, Eyler A, et al. Walking or bicycling to school and weight status among adolescents from Montería, Colombia. J Phys Act Health. 2011; 8(2): S171-S177.

28. Wong BY-M, Faulkner G, Buliung R, Irving H. Mode shifting in school travel mode: examining the prevalence and correlates of active school transport in Ontario, Canada. BMC Public Health. 2011; 11(1): 618.

29. Cooper AR, Page AS, Wheeler BW, et al. Mapping the walk to school using accelerometry combined with a global positioning system. Am J Prev Med. 2010; 38(2): 178-183.

30. Southward EF, Page AS, Wheeler BW, Cooper AR. Contribution of the school journey to daily physical activity in children aged 11-12 years. Am J Prev Med. 2012; 43(2): 201204.

31. Voss C, Winters M, Frazer AD, McKay HA. They go straight home-don't they? Using global positioning systems to assess adolescent school-travel patterns. J Transp Health. 2014; 1(4): 282-287.

32. Klinker CD, Schipperijn J, Toftager M, Kerr J, Troelsen J. When cities move children: development of a new methodology to assess context-specific physical activity behaviour among children and adolescents using accelerometers and GPS. Health Place. 2015; 31: 90-99.

33. Duncan MJ, Mummery WK. GIS or GPS? A comparison of two methods for assessing route taken during active transport. Am J Prev Med. 2007; 33(1): 51-53.

34. Trapp G, Giles-Corti B, Christian H, et al. On your bike! A cross-sectional study of the individual, social and environmental correlates of cycling to school. Int J Behav Nutr Phys Act. 2011; 8(1): 123.

35. Trapp GS, Giles-Corti B, Christian HE, et al. Increasing children's physical activity individual, social, and environmental factors associated with walking to and from school. Health Education Behav. 2012; 39(2): 172-182.

36. Lee C, Li L. Demographic, physical activity, and route characteristics related to school transportation: an exploratory study. Am J Pub Health. 2013; 28(sp3): S77-S88.

37. Murakami E, Wagner DP. Can using global positioning system (GPS) improve trip reporting? Transp Res Part C: Emerg Technol. 1999; 7(2): 149-165.

38. Stopher P, FitzGerald C, Xu M. Assessing the accuracy of the Sydney Household Travel Survey with GPS. Transportation. 2007; 34(6): 723-741.

39. Falb MD, Kanny D, Powell KE, Giarrusso AJ. Estimating the proportion of children who can walk to school. Am J Prev Med. 2007; 33(4): 269-275.

40. Lee C, Zhu X, Yoon J, Varni JW. Beyond distance: children's school travel mode choice. Ann Behav Med. 2013; 45(1): 55-67.

41. Dessing D, de Vries SI, Graham JM, Pierik FH. Active transport between home and school assessed with GPS: a cross-sectional study among Dutch elementary school children. BMC Public Health. 2014; 14(1): 227.

42. Buliung RN, Larsen K, Faulkner GE, Stone MR. The "path" not taken: exploring structural differences in mapped-versus shortest-network-path school travel routes. Am J Public Health. 2013; 103(9): 1589-1596.

43. Harrison F, Burgoine T, Corder K, van Sluijs EM, Jones A. How well do modelled routes to school record the environments children are exposed to?: a cross-sectional comparison of GIS-modelled and GPS-measured routes to school. Int J Health Geogr. 2014; 13: 5.

44. Panter JR, Jones AP, Van Sluijs EM, Griffin SJ. Neighborhood, route, and school environments and children's active commuting. Am J Prev Med. 2010; 38(3): 268-278. 
45. Oreskovic NM, Blossom J, Robinson AI, Chen ML, Uscanga DK, Mendoza JA. The influence of the built environment on outcomes from a "walking school bus study": a cross-sectional analysis using geographical information systems. Geospatial Health. 2014; 9(1): 37.

46. Burgoine T, Jones AP, Brouwer RJN, Neelon SEB. Associations between BMI and home, school and route environmental exposures estimated using GPS and GIS: do we see evidence of selective daily mobility bias in children? Int J Health Geogr. 2015; 14(1): 8.

47. Routledge D, Repetto-Wright R, Howarth C. The exposure of young children to accident risk as pedestrians. Ergonomics. 1974; 17(4): 457-480.

48. DiGuiseppi CG, Rivara FP, Koepsell TD, Polissar L. Bicycle helmet use by children: evaluation of a community-wide helmet campaign. JAMA. 1989; 262(16): 2256-2261.

49. Cote TR, Sacks JJ, Kresnow M-j, et al. Bicycle helmet use among Maryland children: effect of legislation and education. Pediatrics. 1992; 89(6): 1216-1220.

50. Rivara FP, Booth CL, Bergman AB, Rogers LW, Weiss J. Prevention of pedestrian injuries to children: effectiveness of a school training program. Pediatrics. 1991; 88(4): 770-775.

51. Sisiopiku V, Akin D. Pedestrian behaviors at and perceptions towards various pedestrian facilities: an examination based on observation and survey data. Transport Res F: Traffic Psychol Behav. 2003; 6(4): 249-274.

52. Hine J. Pedestrian travel experiences: assessing the impact of traffic on behaviour and perceptions of safety using an in-depth interview technique. J Transp Geogr. 1996; 4(3): 179-199.

53. Lightstone A, Dhillon P, Peek-Asa C, Kraus JF. A geographic analysis of motor vehicle collisions with child pedestrians in Long Beach, California: comparing intersection and midblock incident locations. Inj Prev. 2001; 7(2): 155-160.

54. Pomerantz WJ, Dowd MD, Buncher CR. Relationship between socioeconomic factors and severe childhood injuries. J Urban Health. 2001; 78(1): 141-151.

55. LaScala EA, Gruenewald PJ, Johnson FW. An ecological study of the locations of schools and child pedestrian injury collisions. Accid Anal Prev. 2004; 36(4): 569-576.

56. Warsh J, Rothman L, Slater M, Steverango C, Howard A. Are school zones effective? An examination of motor vehicle versus child pedestrian crashes near schools. Inj Prev. 2009; 15(4): 226-229.

57. Statter M, Schuble T, Harris-Rosado M, Liu D, Quinlan K. Targeting pediatric pedestrian injury prevention efforts: teasing the information through spatial analysis. J Trauma Acute Care Surg. 2011; 71(5): S511-S516.

58. Chakravarthy B, Anderson CL, Ludlow J, Lotfipour S, Vaca FE. A geographic analysis of collisions involving child pedestrians in a large Southern California county. Traffic Inj Prev. 2012; 13(2): 193-198.

59. Blazquez CA, Celis MS. A spatial and temporal analysis of child pedestrian crashes in Santiago, Chile. Accid Anal Prev. 2013; 50: 304-311.

60. Pont K, Ziviani J, Wadley D, Bennett S, Abbott R. Environmental correlates of children's active transportation: a systematic literature review. Health Place. 2009; 15(3): 849-862.

61. Chillón P, Evenson KR, Vaughn A, Ward DS. A systematic review of interventions for promoting active transportation to school. Int J Behav Nutr Phys Act. 2011; 8(1): 10.

62. Mendoza JA, Watson K, Baranowski T, Nicklas TA, Uscanga DK, Hanfling MJ. The walking school bus and children's physical activity: a pilot cluster randomized controlled trial. Pediatrics. 2011; 128(3): e537-e544.

63. Curtis A, Duval-Diop D, Novak J. Identifying spatial patterns of recovery and abandonment in the post-Katrina Holy Cross Neighborhood of New Orleans. Cartogr Geogr Inf Sci. 2010; 37(1): 45-56.

64. Curtis A, Blackburn JK, Widmer JM, Morris JG Jr. A ubiquitous method for street scale spatial data collection and analysis in challenging urban environments: mapping health risks using spatial video in Haiti. Int J Health Geogr. 2013; 12(1): 21. 
65. Curtis A, Curtis JW, Shook E, et al. Spatial video geonarratives and health: case studies in post-disaster recovery, crime, mosquito control and tuberculosis in the homeless. Int J Health Geogr. 2015; 14(1): 22.

66. Burke RC, Cinderich AB, Prince L, Curtis A. Utilizing geographic information systems and spatial video to analyze patterns of secondhand smoke exposure on college campuses. J Am Coll Health. 2015. doi:10.1080/07448481.2015.1031239.

67. Grubesic TH, Matisziw TC. On the use of zip codes and Zip Code Tabulation Areas (ZCTAs) for the spatial analysis of epidemiological data. Int J Health Geogr. 2006; 5(1): 58.

68. Ohio Department of Education. Ohio school report cards, 2013-2014: report card for Helen Arnold Community Learning Center. Ohio State Report Card website. 2015. http://reportcard.education.ohio.gov/Pages/School-Report.aspx?SchoolIRN=009107. Accessed February, 2015.

69. US Census Bureau. Demographic and housing estimates. American Fact Finder: 20092013 American Community Survey 5-year Estimates website. 2015. http://factfinder2. census.gov. Accessed February, 2015.

70. Contour Storyteller [computer program]. Provo, UT2013.

71. Esri ArcGIS 10.2 [computer program]. Redlands, CA; 2013.

72. Hipp JA, Adlakha D, Eyler AE, Chang B, Pless R. Emerging technologies: webcams and crowd-sourcing to identify active transportation. Am J Prev Med. 2013; 44(1): 96-97.

73. Paul M, Haque SME, Chakraborty S. Human detection in surveillance videos and its applications-a review. EURASIP J Adv Signal Process. 2013; 1: 176. 